\title{
Balance of Power between Copyright Owners and Music Teachers
}

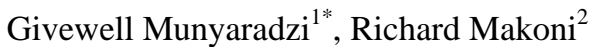 \\ ${ }^{1}$ Great Zimbabwe University, Masvingo, Zimbabwe \\ ${ }^{2}$ Africa University, Mutare, Zimbabwe \\ Email: "ggmax10@gmail.com, makonir@yahoo.com
}

Received November $15^{\text {th }}, 2011$; revised December $18^{\text {th }}$, 2011; accepted December $31^{\text {st }}$, 2011

\begin{abstract}
This contextual paper investigated literature on copyright owners and music educators. The purpose of the paper was to explore the balance of power in the music industry and the education system. In this study the researchers utilized internet resources, available literature in the library and information from informal interview with both music educators and copyright owners. Major findings of the study are as follows: There is a shake balance of power between copyright owners and music educators as music educators seem to be taking advantage of the existing cooperate laws. The TEACH Act does not affect non-members; therefore, the balance of power does not apply to all countries especially developing nations. The raise of modern technology including the internet affected the relationship in intellectual of property. In the work of these findings the researchers recommended that efforts should be made to harmonize stake holders from all countries through the facilitations of the United Nations. Researchers further recommended that technological interrelations is needed in order to monitor internet and related resources to check on abuse or misuse of music resources.
\end{abstract}

Keywords: Music Copyright; Musicians’ Copyright; Music Educators; Intellectual Property Copyright Owners; Copyright Protection; Copyright Violator

\section{Introduction}

The most burning issue in copyright protection and management systems of the rights of the creators of intellectual property is the effort of creating a balance between music teachers and copyright owners. Copyright owners seem to be skeptic about the way music teachers use their works in the education system. Although, most music teachers have a strong argument that they use the works for nonprofit uses, copyright owners always find it difficult to come to terms with the TEACH Act (The Technology, Educational and Copyright Harmonization Act) which gave teachers the right to use all copyright owners' works for non-profit educational uses. However, the most important issue lies in the actual terms of the TEACH Act which seeks to create a balance of power between copyright owners and music teachers. In this way the equilibrium will be based on the level of conviction among the copyright owners, as they need to be convinced that the Act is not only for teachers.

\section{Principles of the TEACH Act}

The relevancy of the principles of the TEACH Act can be felt in the way it attempt to create a balance between music teachers and copyright owners. The Act tries to justify the use of copyrighted works for free in schools and colleges. However, this did not go well with copyright owners as they find it difficult to accept. This means that, these principles while they are welcomed by music teachers, they were received in a different way by copyright owners. The Act gives teachers a different set of rights on top of the already existing fair use. Teachers under

${ }^{*}$ Corresponding author. section 110 (2) are allowed to perform copyrighted works in the classroom. The TEACH Act expands the capacity of teachers' rights to execute and display works as well as making copies integral to such performances. The same material under section 110 (2) can be used by the same teacher when teaching distant students. It is at this stage that copyright owners are worried that the distance between teachers and students can be manipulated by copyright violators as they seek to use their works for free. However, the Act further stated that the copyrighted material should not be available digitally in a format free from technological protection. Therefore, this goes back to the issue of fair use where it is regarded as the only way that can best be viewed as the right of authority for making copies in any given environment (http://wwwuspto.gov).

Section 112 (2) provided some significant changes to the rights of copyright owners and just like other principles of the TEACH Act these changes were greeted with suspicion by copyright owners as the provision gave teachers more rights. Some of the rights which were expanded under section 112 (2) are as follows:

- Transmitting performances of all of a non-dramatic literary or musical work.

- Transmitting reasonable and limited portions of any other performance.

- Transmitting displays of any work in amounts comparable to typical face-face displays (TEACH Act 2002).

Therefore, section 112 (2) managed to provide some of the shortcomings of the previous provisions of section 110 which was failing to restrict the number of people and materials involved in the use of copyrighted material.

Section 110 (2) excluded quite a number of issues. The sec- 
tion only covered accredited non-profit educational organization. Here, the works which was specifically produced for the use in class in the digital distance education market. In this case all works that are sourced individual by students was not mentioned. Some of these works include; books and course packs which students normally purchase or unlawfully secure. This throws the copyrighted works in jeopardy as the day to day activities of copyrighted regulations are violated in schools. As a result of these unclear circumstances the balance of power between music teachers and copyright owners is weakened. Hence, to strengthen this balance of power, principles of section 110 (2) of the TEACH Act ought to be evaluated and its link with the Doctrine of fair use need to be clarified.

\section{The Doctrine of Fair Use}

According to Erickson, Hearn and Halloran (1983) fair use tend to cut the exclusive rights of the copyright owners. The Doctrine came as a result of what was by then regarded as a justified copying. In this case the copying was viewed as fair. The hallmark of this fair use is guided by the potential sales of original work and the amount of the portion of the copyrighted work used. It is through this whole issue of fair use that some of the principles of the TEACH Act were formulated. The general believe and expectation that the copyrighted work is used specifically for classroom lessons. This principle is stated in section 110 (2) of the amended section of the TEACH Act. It is stated that, display of any amount of work should be done in classrooms (Tysver, 1996). However, other sections continue to give more rights to teachers. For example, teachers can have access to copyrighted work and use it anywhere, but given that all technological conditions have been met. The rights of teachers and students were further expanded when section 110 (2) stated that, the copyright work is only for students officially enrolled in that course (Gasaway, 2002). Therefore, there is a need of revisiting the Doctrine of fair use and harmonize its principles with the principles of the TEACH Act. It is through this harmonization approach that the intellectual property can develop a sense of trust that music teachers use their works for fair use and nonprofit making educational purposes.

Striking a balance of power between educators and copyright owners cannot be realized without revisiting the idea of fair use. The coming of the TEACH Act did not mean the eradication of fair use in the copyright regulation. It should be noted that fair use remains relevant because the issues that are covered by the TEACH Act merely focus on small portions of the uses of electronic resources which are sometimes used by music teachers. It only extends to class performances and displays, and does not cover for example digital delivery of supplemental reading material. What it means is that, there is a need to continue to rely on the Doctrine of fair use so that copyright owners will agree on the effective use of the new principle of the TEACH Act. Daniel (1999) also pointed out that, violation of fair use will result in creating an imbalance between teachers and copyright owners. Hence, a balance of power can only be attained through excessive application of some of the issue of the fair use.

\section{Balance of Power between Music Teachers and Copyright Owners}

It is very clear that the balance of power between music teachers and copyright owners is entirely governed by the TEACH Act of 2002. The act created a mutual understanding among copyright owners that their works are not abused by music teachers in the education system. Copyright owners feel robbed to see their works being used by other people such as teachers who did not even put a hand in creating the work. However, the only issue that consoles them is the whole idea that their works are being used to promote education through non-profit channels. On the other hand, music teachers although they are bound by the TEACH Act to use the works for nonprofit education purposes they appear to have nothing to lose. Therefore, it is these unclear characteristics of a modern music teacher which worries copyright owners and as a result they feel threatened by the TEACH Act (Jerry, 1980).

Music teachers just like any other member of the "Free Culture" (which generally refers to the new society of free music which was created by modern technology of internet) are somehow treated as posing potential threat to intellectual property. Creators of intellectual property who are inventors, writers, artists, software engineers, together with a variety of companies that employ them created a shake balance of power between copyright owners mentioned above and teachers. This weak balance of power is twofold; firstly, the intellectual property continues to label music teachers as part and parcel of the general populace that steals their works in the name of "Free Culture". Secondly, the intellectual property do not trust some of the terms of the TEACH Act. One of the terms of the TEACH Act instruct teachers to destroy the copyright material photocopied after a certain period of learning using the same material, for example after completing a given topic or class. This means both teachers and their students will not be allowed to use copyrighted material after completing a certain subject, course or program (Goldstein, 2007). However, the argument which is being put forward by the intellectual property is that, there are no clear provisions and structures that sort of monitoring whether teachers and their students will destroy or keep the copyrighted material after school. Therefore, a balance of power can be created if the TEACH Act is amended as there is a need to put in process a well structured monitoring provision.

\section{Impact of the TEACH Act to Copyright Owners}

The rights of the creators of intellectual property was severely affected by the TEACH Act in quite a number of areas. The fact that teachers are given exclusive rights to make copies as long as they are for educational uses created loopholes which occurred in schools and out of the school environment. In this case the intellectual property is crying foul as the Act tends to favor teachers. Teachers are favored because the fair use already gave them powers to copy and on top of that the TEACH Act further strengthen the powers of music teachers. Hence, the impact is on the fact that, the TEACH Act created teachers as bridges between copyright owners and copyright violators. In the name of "fair use, educational use and non-profit use", the copyrighted material passes through the hands of the teachers and students then to the copyright violators. As a result sales of the copyrighted material such as books, music, movies and so forth will drop because consumers will always find cheaper ones in the streets. Therefore, it is through this channel which was created by the TEACH Act that the copyrighted material is stolen.

The Act tries to protect the rights of owners of intellectual 
property through its restrictions. The Act put much emphasis on the dissemination of information to various educational organizations. These restrictions are realized through time frames of photocopied material, amount of work to be copied and that only enrolled students should have excess to copied material. What it means is that, the Act also provided some kind of a positive impact on the rights of intellectual property, they stand to benefit from some of the conditions of the principles of the TEACH Act. However, it should be noted that the major impact of this Act was felt in the way it handle the issue of distance education. Almost $95 \%$ of the work of distance education is done through the internet; hence, the copyrighted work is prone to violation. The Act failed to protect rights of creators of intellectual property as it cannot control the activities going on through the internet. More important is the fact that, most of the materials send to students who are enrolled on distance education cannot be returned or destroyed as the Act put those requirements. Therefore, creators of intellectual property views the Act as shake and require a lot of changes as it fails to create the required protection of their works from copyright violators.

Furthermore, it can be argued that more advantages are given to teachers by the Act as they keep on hiding under the same principles that created the imbalances. Those law makers who can put some changes seem to be convinced that all is going well because the views of the copyright owners are not heard. This also means that creators of intellectual property should find legal channels in order for them to air their grievances. As a result the battle is not only between teachers and copyright owners, but there is tension among copyright owners as some of them have a feeling that the Act is protecting their works. Powell (2009) pointed out that, some kind of a guiding principle was put into process to govern the protection of intellectual property and it is through these sentiments that some creators of intellectual property feel safe. Therefore, what it means is that there is lack of a unitary voice among the creators of intellectual property and as long as this division existed a balance of power will be difficult to be achieved.

Teachers unlike creators of intellectual property are united as they share the copyrighted material with other schools in an amicable manner and they try to follow the stipulated regulations very well. It is through this unity that their position is strengthened when it comes to issues of copyright regulations. However, changes of section 110 (2) which widens the ground were the copyrighted material is used tries to bring some useful changes which can help to create the much needed balance between the teachers and copyright owners. Some of the changes are indicated below;

- Increased the range of permitted copyrighted materials.

- Increased the number of receiving locations.

- Storage of transmitted material.

- Digitalizing of analogue materials

A closer look at these principles will reveal that the rights of copyright owners are jeopardized and this appear to concur with the above mentioned issues of storage and range of permitted materials. However, this view seems to be strong on paper, but when these principles are applied in schools and other educational institutions, the rights of copyright owners are clearly observed and protected. For example, the issue of digitalizing analogue materials will increase the safety conditions of copyrighted materials as it will be easy for libraries, labs and administrators to protect the materials from spilling in the hands of copyright violators. On top of this administrators together with the libraries will be able to clearly control as well as monitoring the use of copyrighted material by both the teachers and their students. Therefore, so much can be said about the fact that the Act is heavily in favor of teachers, but it must be observed that, too much restriction on copyrighted works will also create imbalances as buyers of these works will fail to purchase these works.

\section{Conclusion}

A balance of power between music teachers and copyright owners can only be realized if all the two sides are certified with the current state of affairs in the free world where there is a lot of copyright infringement. The new technology creates the free culture and this habit should also be controlled by the technology as it is a modern problem. The same issue applies to the tension between copyright owners and teachers, there is a need of providing some changes to the TEACH Act so that it will handle the imbalances which the Act indirectly created in an amicable way. Therefore, the argument which was poised by the discussion was on the ability of the Act to convince creators of intellectual property that their works are safe in the hands of teachers and in this way a balance between the two can be created.

\section{REFERENCES}

Erickson, J. G, Hearn, E. R., \& Halloran, M. E. (1983). Musician's guide to copyright (Revised edition). New York: Charles Scribner's Sons.

Goldstein, P. (2007). Intellectual property. New Caledonia: Penguin group Inc.

Jerry, W. (1980). Negotiating and contracting. Association of Colleges, University and Community Arts Administrators Inc.

Laura, N. G. (25 November 2002). TEACH Act-Amended Section 110(2). http://www.unc.edu/-unclng/Teach.htm

Lehman A. B. (1998). Final report to the commissioner on the conclusion of the conference on fair use.

http://www.uspto.gov/web/offices/dcom/olia/confu/confurep

Powell, D. S. (2009). An introduction to education, choosing your teaching path. Cranbury, NJ: Pearson Education, Inc.

Tysver, D. A. (1996). Fair use in copyright. Bitlaw: A Resource on Technology Law. http://www.bitlaw.com/copyright/fairuse.html. 